\title{
Regional Atrial Blood Flow in Dogs Effect of Hypertrophy on Coronary Flow Reserve
}

Robert P. Bauman, Judith C. Rembert, and Joseph C. Greenfield, Jr. Department of Medicine, Division of Cardiology, Duke University Medical Center, Durham, North Carolina 27710; and Medical Service (Cardiology Section) and Research Service, Veterans Administration Medical Center, Durham, North Carolina 27705

\begin{abstract}
Little is known regarding regional atrial blood flow responses during varying hemodynamic states in both the normal and hypertrophied atria. This study was undertaken to develop a canine model of chronic atrial hypertrophy and to define in both this group and in normal dogs the regional blood flow response to acute atrial fibrillation and to measure coronary flow reserve. In the 12 dogs with atrial but not ventricular hypertrophy the mean left and right atrial weights were 75 and $47 \%$ respectively greater than in the normal group. Blood flow in the normal dogs was less in the appendage than in the nonappendage region for both atria and increased significantly during atrial fibrillation. Similar findings were noted in the hypertrophy group except that during control conditions the left atrial appendage flow was similar to the nonappendage flow. Minimal vascular resistance for the hypertrophy group, $39 \pm 3$ was significantly $(P<0.05)$ greater when compared to the normal group $28 \pm 2 \mathrm{mmHg} / \mathrm{cm}^{3}$ per min per $\mathrm{g}$. Thus, significant regional blood flow differences occur in both the normal and hypertrophied atria. In addition, atrial hypertrophy does not alter the autoregulatory capacity to the hemodynamic stress of atrial fibrillation but does reduce coronary flow reserve.
\end{abstract}

\section{Introduction}

Although the factors that control coronary vasomotion have been studied extensively in both chronic right (1) and left (2-5) ventricular hypertrophy, there are no studies published to date which define the effects of atrial hypertrophy on atrial myocardial blood flow. In implementing the studies described in this report, dogs were used in which insufficiency or stenosis of either the aortic or mitral valve had been produced surgically approximately six years previously. These valvular abnormalities resulted in marked left and right atrial hypertrophy, but were not of sufficient hemodynamic consequence to result in ventricular hypertrophy. Since there is a dearth of information in dogs regarding the relationship between atrial mass and body weight, it was necessary to first define this relationship in a group of normal dogs and to test whether or not the chronic surgical dogs had atrial hypertrophy.

There are several reports that define the blood flow responses of both the right and left atria to alterations in hemo-

Address reprint requests to Dr. R. P. Bauman, Room B3003, Veterans Administration Medical Center, Durham, NC 27705.

Presented in part at the Annual Meeting of the American Federation for Clinical Research, 29 April 1988, in Washington, DC.

Received for publication 7 June 1988 and in revised form 8 November 1988

The Journal of Clinical Investigation, Inc.

Volume 83, May 1989, 1563-1569 dynamic conditions (6-8). Since different regions within each atria are quite variable in shape and architecture, it is reasonable to postulate that the blood flow response to differing hemodynamic conditions might vary. However, there are no published systematic studies of regional atrial blood flow following perturbations in the hemodynamic state.

Previous studies have indicated that in the dog with left ventricular hypertrophy, minimal vascular resistance is elevated reflecting a decrease in coronary flow reserve $(2,4)$. Thus, it would be of considerable interest to determine whether a similar phenomenon occurs in the chronically hypertrophied atrium.

This study was designed to test in both normal and hypertrophied atria, the regional blood flow response: $(a)$ to atrial pacing at 120 beats/min; $(b)$ to acute atrial fibrillation and (c) to measure coronary flow reserve. In carrying out these studies the data were obtained in chronically instrumented awake animals in order to avoid the hemodynamic consequences of anesthesia and acute surgical trauma.

\section{Methods}

Approximately seven years ago our laboratory produced a colony of purebred foxhounds with surgically induced valvular heart disease. These puppies underwent a right thoracotomy at 10-12 wk of age. In approximately half of them, mitral insufficiency was created by introducing through the left ventricular wall below the level of the A-V groove a specially designed surgical hook-knife to randomly sever multiple chordae tendinae until mean left atrial pressure increased $\sim 50 \%$. In the others, aortic stenosis was produced by plicating the noncoronary and the right coronary cusps with a single 6-0 prolene suture, via a small aortatomy which was closed with a 2-0 prolene pledgit. After recovery, they were housed in a standard indoor/outdoor run, received a routine diet, daily heart worm preventative but no prophylactic antibiotics or exercise training program. The presence of valvular disease was documented and left ventricular wall thickness and chamber size were estimated approximately each 6 mo with two-dimensional echocardiograms (model 2136A; Hewlett-Packard Corp., Andover, MA). 14 of these hounds, 11 with mitral and 3 with aortic surgery, did not have sufficient valvular disease to produce left ventricular hypertrophy but 12 apparently did develop atrial enlargement. All were approximately $6 \mathrm{yr}$ of age when studied. These dogs formed the basis for this report.

18 Class I hound type adult dogs served as controls. Of these, seven were used to measure atrial blood flow and the rest were used only for the atrial anatomic measurements. All animals were studied according to a protocol approved by the Animal Care and Use Committees of both the Duke University and the Durham Veterans Administration Medical Centers. At the time of study, the dogs were afebrile, in normal sinus rhythm, without signs of heart failure and had normal hematocrits. On the day of study the dogs were weighed and brought to the laboratory where the room lights were dimmed and noise was kept to a minimum. Morphine sulfate $0.5-0.75 \mathrm{mg} / \mathrm{kg}$ i.m. was administered for mild analgesia. Each was gently positioned into the left lateral position on a fluoroscopic table which had an inflated air mattress. Electrocardiographic leads were attached to the extremities and connected to a Hewlett-Packard 8811A bioelectric amplifier for continu- 
ous monitoring of lead II on the Hewlett-Packard model 780-6A visoscope and oscillograph. Local anesthesia was accomplished using $2 \%$ lidocaine hydrochloride injected subcutaneously via a 26-gauge needle at the insertion site of percutaneous sheaths and cutdowns. The right external jugular and carotid vessels were palpated, isolated and cannulated with 8F USCI sheaths. Under direct fluoroscopic visualization with a C arm x-ray unit (Philips Medical Systems, Inc., Shelton, CT), a 40-cm, $2 \mathrm{~mm}$ i.d. polyvinyl chloride pressure catheter was advanced into the ascending aorta. Similarly the left external jugular was cannulated with a USCI $8 \mathrm{~F}$ sheath and a dilator was advanced into the right atrium over a guidewire. The wire was replaced with a Brockenbrough needle which was advanced through the interatrial septum into the left atrium as described by Phillips et al. (9). The needle and dilator were removed and replaced with a 7F Swan Ganz double lumen catheter (American-Edwards Laboratories, Anosco, Puerto Rico). The balloon was inflated with $1.5 \mathrm{~cm}^{3}$ of air and the distal lumen was utilized to measure left atrial pressure. Both aortic and left atrial catheters were connected to pressure transducers (P23Db; Gould-Statham Instruments, Oxnard, CA) connected to Hewlett-Packard 8805 carrier amplifiers. The transducers were zeroed to atmospheric pressure at mid chest level. All data were recorded continuously using an 8-channel Hewlett-Packard 7785A direct writing oscillograph and a 3520B FM magnetic tape recorder. An atripace flare pacing electrode (Mansfield Scientific, Inc., Mansfield, MA) was advanced via the right external jugular sheath into the right atrium. The electrode leads were connected to a Grass model stimulator (model S44; Grass Instrument Co., Inc., Quincy, MA) and gently positioned within the atrial chamber until capture was maintained with the lowest possible threshold. After instrumentation was completed and a stable environment achieved, $\sim 3 \mathrm{~h}$ had elapsed since the morphine administration. Thus, hemodynamics and blood flow measurements were performed in the awake, unanesthetized state.

The protocol was designed to measure atrial blood flow sequentially during three pertubations: (a) atrial pacing at $120 \mathrm{bpm}$ (control); (b) acute atrial fibrillation, induced spontaneously or by atrial pacing at a rate of $20 \mathrm{~Hz}(6)$; and (c) during maximum vasodilation, induced by infusing adenosine $1 \mathrm{mg} / \mathrm{kg}$ per min until a steady hemodynamic state was achieved (10). Atrial fibrillation was maintained throughout the adenosine infusion.

Myocardial blood flow was measured using $11 \pm 0.25-\mu \mathrm{m}$ diam microspheres labeled with one of seven different gamma emitting nuclides: Iodine-125, Cerium-141, Chromium-51, Tin-113, Ruthenium103, Niobium-95, and Scandium-46. Microspheres were diluted in $10 \%$ Dextran so that $1 \mathrm{~cm}^{3}$ contained $\sim 3 \times 10^{6}$ microspheres. Thorough mixing was achieved by alternating the use of an ultrasonic bath and a vortex. The suspension was injected into the left atrium and flushed with approximately $6 \mathrm{~cm}^{3}$ room temperature saline. Simultaneously, reference blood samples were withdrawn from the aortic catheter using a previously calibrated withdrawal pump (model 1210; Harvard Apparatus Co., Natick, MA).

Upon completion of blood flow measurements each animal was anesthetized using sodium thiamylal $50 \mathrm{mg} / \mathrm{kg}$ and the mediastinal vessels were isolated via a left thoracotomy. Aortic arch vessels were occluded, cannulated, and connected to a perfusion system. The heart was stopped with $10 \mathrm{~cm}^{3}$ of $10 \% \mathrm{KCl}$ administered into the left atrium while cross-clamping the descending aorta. The myocardium was perfused with $\sim 500 \mathrm{~cm}^{3}$ of iced normal saline followed by $\sim 1,000 \mathrm{~cm}^{3}$ of $10 \%$ iced buffered formalin via the coronary arteries at $100 \mathrm{~mm} \mathrm{Hg}$ or the mean control pressure during life. A $1-\mathrm{cm}$ incision in the right ventricular free wall vented the coronary sinus return into the thoracic cavity.

The heart was removed and placed in $10 \%$ buffered formalin for an additional $72 \mathrm{~h}$. Atrial and ventricular myocardium were stripped carefully of all connective tissue. Since atrial myocardium encircles the base of the vena cavae and pulmonary veins, these vessels were trimmed to within $\sim 8-10 \mathrm{~mm}$ of the atrial wall to include this muscle in the atrial mass measurements (11). The free walls of each atria were separated along natural borders from the ventricles without loss of atrial myocardium. Atrial separation was completed by severing the septum along the surface of the left ventricular myocardium. The right atrium was isolated from the left along the plane of the interatrial septum, which is contiguous with the left atrial free wall. When possible this separation occurred along natural anatomic planes formed by invagination of right atrial myocardium. However, frequently a number of bridging strands of atrial myocardium had to be cut. After separation, both atria were weighed. Similarly, right and left ventricles were separated along anatomic planes and weighed. Atrial and ventricular weights were divided by body weights to produce the respective myocardial to body weight $(\mathrm{g} / \mathrm{kg})$ ratios. The interatrial septum was separated from the left atria and both the right and left atria were sectioned further into nine separate sections: top, floor, and edge of the appendage region; anterior, lateral and posterior of the side region and anterior, middle and posterior of the roof region as shown in Fig. 1. Delineation of the border of the appendage to the nonappendage region was not precise enough to allow weight comparison between appendage and nonappendage regions. The left ventricle was sectioned as previously described by our laboratory (12). All atrial and ventricular tissue samples were individually weighed and placed in vials. Gamma emissions of each vial of tissue and reference blood were counted for $10 \mathrm{~min}$ in a gamma spectrophotometer, Packard-Canberra Series 35-Plus, with window settings corresponding to the peak energies of each isotope.

The flow for each isotope of each tissue sample was calculated using the formula: $Q \mathrm{c}=Q \mathrm{r} \times(\mathrm{Ct} / \mathrm{Cr}) ; Q \mathrm{c}=$ myocardial blood flows $\left(\mathrm{cm}^{3} /\right.$ $\min ), Q \mathrm{r}=$ rate of reference sample collection $\left(\mathrm{cm}^{3} / \mathrm{min}\right), \mathrm{C}=$ total gamma counts of each isotope minus the background counts of each isotope for each tissue sample $(t)$ and each reference blood collection, (r). The flow $\left(\mathrm{cm}^{3} / \mathrm{min}\right)$ of each sample was divided by the sample weight (grams) and expressed as $\mathrm{cm}^{3} / \mathrm{min}$ per $\mathrm{g}$ of tissue (12). The microsphere method described above has been shown in our laboratory to be adequate to test for differences in segmental atrial blood flow (13).

Arterial and left atrial pressures and the heart rate were measured directly from the oscillograph records. An index of vascular resistance in the atrial and ventricular myocardium was calculated by dividing mean arterial pressure by normalized flow and was expressed as $\mathrm{mmHg} / \mathrm{cm}^{3}$ per min per $\mathrm{g}$ of tissue. Data were reported as mean \pm SEM.

Data analyses were performed using Student's paired $t$ test for comparisons of flow within each animal and one-way analysis of variance test for comparison of flows between normal and hypertrophied

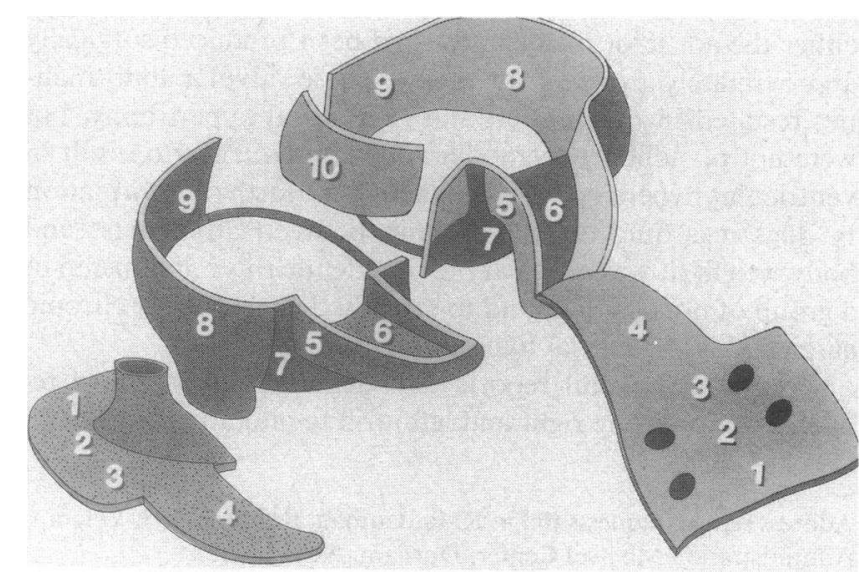

Figure 1. Schematic diagram of the left (clear area) and right (stippled area) atria indicating how the regional sections were cut. Areas 1-3 represent the roof region; 4-6 are from the appendage region and; 7-9 were termed the side region of each atrium, respectively. Number 10 is the interatrial septum and was included in the mean left atrial data. 
animals. When appropriate, the critical value of $t$ was corrected for multiple comparisons by the Bonferroni method (14). Linear regression was calculated and correlation coefficients obtained. Differences in regression lines were compared using the $f$ test.

\section{Results}

The mean body weight for the 18 normal and 14 valvular surgery dogs were similar, $29 \pm 2 \mathrm{~kg}$; (range, 18 to $41 \mathrm{~kg}$ ) and $30 \pm 2 \mathrm{~kg}$; (range, 16 to $43 \mathrm{~kg}$ ), respectively. The mean left ventricular weight for the valvular surgery and control dogs was $141 \pm 12$ and $121 \pm 7 \mathrm{~g}$, respectively and the mean right ventricular weight was $57 \pm 4$ and $51 \pm 4 \mathrm{~g}$, respectively. Neither right nor left ventricular weights were significantly different between the two groups, $P>0.2$ and $P>0.1$, respectively. The ratio of the left ventricular weight $(\mathrm{g})$ to the body weight $(\mathrm{kg})$ for the normal dogs was $4.3 \pm 0.1 \mathrm{~g} / \mathrm{kg}$ and the dogs with valvular surgery was $4.7 \pm 0.3 \mathrm{~g} / \mathrm{kg}$ and was not significantly different $(P>0.1)$.

In Fig. 2, the regression line \pm 2 SE for the normal dogs relating the left atrial weight and the body weight is illustrated. The correlation coefficient was $r=0.94$. The individual left atrial weights for each of the valvular surgery dogs are plotted. In three dogs, the left atrial weight was within the range of normal, thus the blood flow data from these dogs were included in the data for the normal dogs and represents measurements from a sham preparation. The mean left atrial weight in the normal dogs was $10.3 \pm 0.8 \mathrm{~g}$ and was $18.0 \pm 1.3 \mathrm{~g}$ for the 11 valvular surgery dogs in whom hypertrophy was present. Thus, the mean left atrial weight of the hypertrophy group was $75 \%$ greater than normal. The mean left atrial/body weight ratio of the normal and hypertrophied dogs differed significantly; $0.35 \pm 0.01$ and $0.62 \pm 0.02(\mathrm{~g} / \mathrm{kg})(P<0.00001)$, respectively. When the left atrial/body weight ratio was plotted as a function of body weight, the slope was not significantly different from zero indicating that the use of left atrial body weight ratio to define the presence of left atrial hypertrophy is valid over the range of body weights found in this study.

Similar data illustrating the relationship between the right atrial weight and body weight in both the normal and valvular surgery dogs is illustrated in Fig. 3. The correlation coefficient for the line of regression in normal dogs was $r=0.95$. Two of the atria from the valvular surgery hearts were within the normal range and the data were treated similarly as with the left atrium. The mean right atrial weights were $10.0 \pm 0.8 \mathrm{~g}$ for the normal dog and $14.7 \pm 1.0 \mathrm{~g}$ for the dogs with right atrial hypertrophy indicating a $47 \%$ increase in mean atrial weight. The

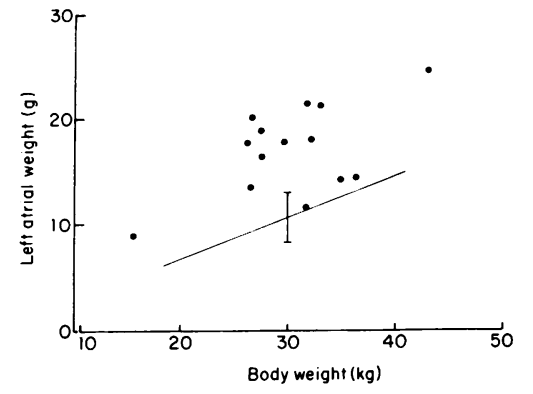

Figure 2. Individual left atrial weights for each of the dogs who had valvular surgery is plotted (ordinate) against the body weight ( $a b$ scissa). The regression line $\pm 2 \mathrm{SE}$ is illustrated for the 18 normal dogs. Note that the atrial weight for three of the dogs with valvular surgery fall within the normal range.

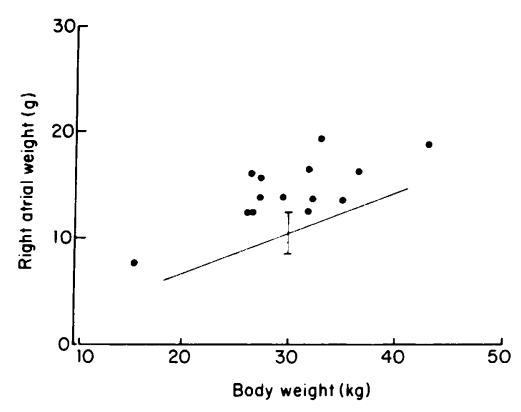

Figure 3. Individual right atrial weights for each of the dogs who had valvular surgery is plotted (ordinate) against the body weight (abscissa). The regression line $\pm 2 \mathrm{SE}$ is illustrated for the 18 normal dogs. Note that the atrial weight for two of the dogs with valvular surgery fall within the normal range.

mean right atrial/body weight ratio of the normal and hypertrophied dogs was $0.35 \pm 0.01$ and $0.50 \pm 0.02 \mathrm{~g} / \mathrm{kg}(P$ $<0.000001$ ), respectively. As was found in the left atrium, a plot of right atrial body weight ratio as a function of body weight yielded a slope which did not differ significantly from zero indicating that the use of right atrial/body weight ratio to define hypertrophy over this body weight range is valid. In comparing the regression lines of right and left atrial weights and body weights of the normal dogs (Figs. 2 and 3) the $y$ intercepts of -0.769 and -1.009 , respectively, and the slopes of 0.38 and 0.39 , respectively, were not significantly different.

Blood flow data were obtained in seven normal dogs. The two valvular surgery dogs in which both the atria were normal in weight were considered shams and were included in the control group bringing the total to nine. The one dog with right but not left atrial hypertrophy was considered to have hypertrophy when comparing the ventricular flow and resistance data.

The hemodynamic data for these dogs obtained during the three interventions are given in Table I. No significant differences were found between normal and hypertrophied dogs during atrial pacing at $120 \mathrm{bpm}$ or acute atrial fibrillation. The mean blood pressure during adenosine infusion was significantly lower than that during the control state for both the normal and hypertrophy dogs. The ventricular rate was significantly higher during adenosine infusion in the normal dogs when compared to the rate recorded during control.

In both the normal and dogs with atrial hypertrophy the blood flow and the vascular resistance index were calculated for the septum and each of the nine individual sections for

Table I. Hemodynamic Data

\begin{tabular}{|c|c|c|c|c|c|c|}
\hline & \multicolumn{2}{|c|}{ AP 120} & \multicolumn{2}{|c|}{$\mathrm{AF}$} & \multicolumn{2}{|c|}{$\mathrm{AF}+\mathrm{ADN}$} \\
\hline & $\mathbf{N}$ & $\mathbf{H}$ & $\mathrm{N}$ & $\mathbf{H}$ & $\mathrm{N}$ & $\mathbf{H}$ \\
\hline AOP & $110 \pm 6$ & $115 \pm 6$ & $106 \pm 6$ & $108 \pm 4$ & $70 \pm 6^{*}$ & $81 \pm 2^{*}$ \\
\hline LAP & $2.6 \pm 1.1$ & $2.8 \pm 1.3$ & $3.3 \pm 1.0$ & $4.9 \pm 0.9$ & $4.5 \pm 1.8$ & $3.9 \pm 1.2$ \\
\hline VR & $93 \pm 12$ & $108 \pm 14$ & $90 \pm 13$ & $91 \pm 5$ & $176 \pm 15^{*}$ & $140 \pm 26$ \\
\hline
\end{tabular}

The mean $\pm S E M$ for aortic pressure (AOP) and left atrial pressures (LAP) in $\mathrm{mmHg}$ and the ventricular rate beats per minute (VR) are listed for both normal $(\mathrm{N})$ and hypertrophied $(\mathrm{H})$ atria dogs during atrial pacing at $120 \mathrm{bpm}$ (AP 120), acute atrial fibrillation (AF) and $\mathrm{AF}+$ adenosine infusion ( $\mathrm{AF}+\mathrm{ADN})$.

* A significant $(P<0.05)$ difference from AP 120 and AF. 
both the right and left atria during each of the three interventions (see Fig. 1). The data from each section were compared to determine if any consistent variation within each of the three regions (appendage, roof, and sides) could be demonstrated. Since no significant differences were found $(P>0.05)$, the weighted average for each of the three regions was computed for each dog. Subsequently, comparisons were made between these regions for both the normal and atrial hypertrophy dogs. Although no systematic differences were found between segments, segmental flows did vary within a given region. For example, in normal dogs during atrial pacing at $120 \mathrm{bpm}$, mean segmental flow varied from the weighted average flow of appendage, roof, and sides by $1 \pm 14,5 \pm 25$, and $5 \pm 27 \%$, respectively, in left atria and $1 \pm 18,1 \pm 18$, and $6 \pm 26 \%$, respectively, within right atria. Similar variations occurred during atrial fibrillation and while infusing adenosine $1 \mathrm{mg} / \mathrm{kg}$ per min in normal and hypertrophied atria.

Weighted averages of the nine segmental flows $\left(\mathrm{cm}^{3} / \mathrm{min}\right.$ per $\mathrm{g}$ ) from both the right and left atria were calculated for each atria during the interventions of atrial pacing at $120 \mathrm{bpm}$, atrial fibrillation and adenosine infusion $1 \mathrm{mg} / \mathrm{kg}$ per $\mathrm{min}$. In the normal animals, mean left atrial blood flows were $0.51 \pm 0.06,1.31 \pm 0.17$, and $3.04 \pm 0.35$, respectively, and mean right atrial blood flows were $0.30 \pm 0.04,0.75 \pm 0.11$, and $2.34 \pm 0.28$, respectively. In the hypertrophy animals, mean left atrial blood flows were $0.69 \pm 0.09,1.59 \pm 0.06$, and $2.67 \pm 0.31$, respectively, and mean right atrial blood flows were $0.27 \pm 0.05,0.71 \pm 0.08$, and $1.76 \pm 0.15$, respectively. In four of the hypertrophied dogs, spontaneous atrial fibrillation occurred during instrumentation. Thus, the flow data during atrial pacing at $120 \mathrm{bpm}$ were obtained in only six dogs for the left atria and seven for the right atria. In both the normal and the hypertrophy dogs, atrial blood flows were greater in the left when compared to the right atria $(P \leq 0.008)$ and a progressive increase in flow in both the right and left atria occurred with each intervention.

In comparing the three regions of both the right and left atria for the normal and hypertrophied atria dogs during the three interventions no consistent significant differences $(P$ $>0.05$ ) were found between the roof and side regions. The only exception was in the left atria of the normal dogs during atrial pacing at $120 \mathrm{bpm}$, where blood flow to the sides differed significantly from the roof regions, $0.61 \pm 0.06$ and $0.49 \pm 0.07$ $\mathrm{cm}^{3} / \mathrm{min}$ per $\mathrm{g}(P<0.01)$, respectively. For further comparisons the weighted average of roof and side regions were compared to blood flows and resistances for the atrial appendage regions.

In Table II, the appendage and nonappendage regional atrial blood flow of the right atrium in normal and hypertrophied atria dogs during each intervention are given. Blood flow was significantly lower in the appendage region when compared to the nonappendage region for both normal and hypertrophied atria during atrial pacing at $120 \mathrm{bpm}, 48 \pm 5 \%$ and $39 \pm 9 \%$, respectively, and during atrial fibrillation $28 \pm 6 \%$ and $21 \pm 8 \%$, respectively. During adenosine infusion, the flows were significantly less $(15 \pm 4 \%)$ in the appendage region when compared to the nonappendage region in normal right atria but did not differ in the hypertrophied right atria.

In Table II, similar comparisons of left atrial blood flow for the appendage and nonappendage regions are given. In the normal dogs during atrial pacing at $120 \mathrm{bpm}$, flow to the appendage region was lower by $31 \pm 9 \%$ when compared to the nonappendage region, a pattern similar to that in the right atria. However, a different pattern was noted in the hypertrophied left atria where no differences between appendage and nonappendage regional flows were noted during atrial pacing at $120 \mathrm{bpm}$. In both groups of dogs flows to the two regions were not different during acute atrial fibrillation $(P>0.05)$. During adenosine infusion, the appendage regions showed a higher flow than the nonappendage regions in both the normal $(19 \pm 5 \%)$ and hypertrophied $(14 \pm 4 \%)$ left atria.

It is apparent that for both the right and left atria (Table II) the appendage region undergoes a greater increase in flow from atrial pacing at $120 \mathrm{bpm}$ to the adenosine infusion. In the normal dogs, the right atrial appendage flow increased $1,142 \pm 213 \%$ while the nonappendage region flow increased $707 \pm 175 \%$. Similarly, left atrial appendage flow increased $921 \pm 273 \%$ and nonappendage by $495 \pm 137 \%$. These differences are statistically significant $(P<0.002)$ and $(P<0.03)$, respectively.

Table II. Regional Atrial Blood Flow

\begin{tabular}{|c|c|c|c|c|c|c|}
\hline & \multicolumn{2}{|c|}{ AP 120} & \multicolumn{2}{|c|}{$\mathrm{AF}$} & \multicolumn{2}{|c|}{$\mathrm{AF}+\mathrm{ADN}$} \\
\hline & $\mathbf{N}$ & $\mathbf{H}$ & $\mathbf{N}$ & $\mathbf{H}$ & $\mathbf{N}$ & $\mathbf{H}$ \\
\hline \multicolumn{7}{|l|}{ Right atria } \\
\hline & (8) & (7) & (8) & (9) & (8) & (9) \\
\hline APPEN & $0.20 \pm 0.03^{*}$ & $0.19 \pm 0.04^{*}$ & $0.60 \pm 0.07^{*}$ & $0.60 \pm 0.08^{*}$ & $2.15 \pm 0.29^{*}$ & $1.74 \pm 0.23$ \\
\hline NONAPPEN & $0.39 \pm 0.05$ & $0.33 \pm 0.06$ & $0.88 \pm 0.14$ & $0.78 \pm 0.08$ & $2.48 \pm 0.28$ & $1.81 \pm 0.15$ \\
\hline \multicolumn{7}{|l|}{ Left atria } \\
\hline & (9) & (6) & (8) & (9) & (8) & (9) \\
\hline APPEN & $0.38 \pm 0.07^{*}$ & $0.73 \pm 0.10$ & $1.54 \pm 0.22$ & $1.86 \pm 0.14$ & $3.48 \pm 0.39^{*}$ & $2.98 \pm 0.34^{*}$ \\
\hline NONAPPEN & $0.57 \pm 0.07$ & $0.69 \pm 0.10$ & $1.24 \pm 0.18$ & $1.56 \pm 0.10$ & $2.97 \pm 0.37$ & $2.61 \pm 0.26$ \\
\hline
\end{tabular}

Mean \pm SEM appendage (APPEN) and nonappendage (NONAPPEN) atrial blood flows $\left(\mathrm{cm}^{3} / \mathrm{min}\right.$ per g) of right atria and left atria in normal (N) and hypertrophied (H) dogs during atrial pacing at $120 \mathrm{bpm}$ (AP 120) atrial fibrillation (AF) and AF + adenosine infusion (AF + ADN). * A significant difference between appendage and nonappendage regional flows $(P \leq 0.03)$. The number of dogs for each intervention is given in parentheses. 


\begin{tabular}{|c|c|c|c|c|c|c|}
\hline & \multicolumn{2}{|c|}{ AP 120} & \multicolumn{2}{|c|}{$\mathrm{AF}$} & \multicolumn{2}{|c|}{$\mathrm{AF}+\mathrm{ADN}$} \\
\hline & APPEN & NONAPPEN & APPEN & NONAPPEN & APPEN & NONAPPEN \\
\hline \multicolumn{7}{|c|}{$\begin{array}{l}\text { Right } \\
\text { atria }\end{array}$} \\
\hline$N$ & $622 \pm 03$ & $306 \pm 30$ & $198 \pm 33$ & $148 \pm 33$ & $34 \pm 3^{*}$ & $29 \pm 2 *$ \\
\hline $\mathbf{H}$ & $766 \pm 160$ & $449 \pm 103$ & $207 \pm 29$ & $153 \pm 21$ & $52 \pm 6$ & $47 \pm 5$ \\
\hline \multicolumn{7}{|c|}{ Left atria } \\
\hline$N$ & $330 \pm 46^{*}$ & $206 \pm 17$ & $76 \pm 14$ & $103 \pm 23$ & $21 \pm 2^{*}$ & $25 \pm 3^{*}$ \\
\hline H & $172 \pm 21$ & $183 \pm 25$ & $61 \pm 5$ & $71 \pm 5$ & $29 \pm 2$ & $33 \pm 3$ \\
\hline
\end{tabular}

Mean \pm SEM resistance index $\left(\mathrm{mmHg} / \mathrm{cm}^{3}\right.$ per min per $\mathrm{g}$ ) of appendage (APPEN) and nonappendage (NONAPPEN) regions in normal (N) and hypertrophied (H) right atria and left atria during atrial pacing at $120 \mathrm{bpm}$ (AP 120), acute atrial fibrillation (AF) and acute atrial fibrillation with adenosine $(\mathrm{AF}+\mathrm{ADN}) 1 \mathrm{mg} / \mathrm{kg}$ per min.

* A significant difference between normal and hypertrophied atria $(P \leq 0.04)$.

The resistance index $\left(\mathrm{mmHg} / \mathrm{cm}^{3}\right.$ per min per $\left.\mathrm{g}\right)$ was calculated for each atria during atrial pacing at $120 \mathrm{bpm}$, atrial fibrillation and adenosine infusion (i.e., minimal vascular resistance). The mean resistance indices were $385 \pm 32,167 \pm 34$, and $31 \pm 2$, respectively, in normal right atria and $539 \pm 119$, $168 \pm 23$, and $48 \pm 4$, respectively, in hypertrophied right atria. Similarly, the mean resistance indices were $227 \pm 17,98 \pm 23$, and $24 \pm 2$, respectively, in normal left atria and $179 \pm 22$, $168 \pm 23$, and $32 \pm 3$, respectively, in hypertrophied left atria. There is a progressive decrease in atrial resistance for both the normal and hypertrophied atria during the three interventions. The resistance index during adenosine infusion was significantly higher for both the right and left atria in the hypertrophied atria dogs $(P<0.02)$ when compared to the control dogs; whereas no significant differences were noted during the other interventions.

In Table III, the resistance index for the appendage and nonappendage regions of the right atria are given. Note that the resistance is significantly higher $(P<0.02)$ in the hypertrophied atria during adenosine infusion for both the appendage and nonappendage regions. Similar resistance data for the appendage and nonappendage regions of the left atria are given in Table III. During atrial pacing $120 \mathrm{bpm}$, resistance was lower in the appendage region of hypertrophied atria when compared to normal $(P<0.01)$. Again, note that the minimal resistance during adenosine infusion is significantly higher $(P$ $<0.04$ ) for both the appendage and nonappendage regions of the hypertrophied atria when compared to the normal atria.

The resistance index $\left(\mathrm{mmHg} / \mathrm{cm}^{3}\right.$ per min per $\left.\mathrm{g}\right)$ during adenosine infusion for the left ventricle of normal dogs was $21 \pm 2$ and for the atrial hypertrophy dogs was $24 \pm 4$. These differences were not statistically significant $(P>0.3)$. For both right and left ventricles the mean minimal resistance was significantly lower than mean minimal atrial resistance, in both normal and hypertrophy groups $(P<0.05)$.

\section{Discussion}

In the dogs used in this study, the hemodynamic consequences of valvular surgery were insufficient to produce significant left ventricular hypertrophy. All dogs were clinically healthy and had never shown any symptoms of congestive heart failure. The majority of the surgery dogs developed marked left atrial enlargement averaging $75 \%$ greater than the normal dogs without any evidence of ventricular hypertrophy. No differences in mean left atrial pressures could be demonstrated, at least during resting conditions, between the control and hypertrophy dogs. At the time of sacrifice the valves were abnormal. Although we could not quantitate the degree of insuffciency or stenosis, two-dimensional echocardiography clearly indicated abnormal valve motion. Thus, in these dogs it is likely that either during exercise or other forms of stress which resulted in an increase in cardiac output, the left atria may have been subjected to increased filling pressures sufficient to initiate atrial hypertrophy.

It is possible that the hypertrophy response occurred as a consequence of nonhemodynamic factors associated with this animal model, such as age. Using echocardiographic measurements, Gardin et al. (15), reported a 16\% increase in atrial dimension as a function of advanced age in patients without other evidence of cardiac disease. Whether or not this finding is applicable to the dog is unknown. However, even if atrial size increases with age in dogs, there are at least four reasons why this finding is not of primary importance to our study: $(a)$ the surgical dogs in this study were approximately six years of age. Although the age of the control dogs is unknown, judging by the general condition they were not young and the age of the two groups probably is not dissimilar. $(b)$ Six years of age in a dog is not elderly and thus not comparable to the ninety years in the patients reported by Gardin et al. (15). (c) The degree of atrial hypertrophy is quite marked in the surgical dogs and is considerably greater than the reported increase in atrial dimensions (15). (d) Finally, two of the surgical dogs did not develop hypertrophy and thus are shams. Other pertinent factors such as type, weight, and general condition were similar so that the seven control dogs and the two shams would seem to be a reasonable group to define the normal atrial size and blood flow for comparison to the dogs with atrial hypertrophy. Since the surgical procedures were carried out at 10 to $12 \mathrm{wk}$ of age, the increase in atrial mass is probably due entirely to the growth of existing myocytes. Primary myocyte division has been shown to cease in the dogs shortly after birth (16). 
An extremely interesting finding was the concomitant hypertrophy of the right atrium, an average of $47 \%$ greater than in the normal dogs. It seems reasonable to speculate that the right atrial hypertrophy may have been related to the same, although less intensive biologic process which resulted in left atrial hypertrophy. Since the right side valves were normal it is unlikely that in these animals the right atria were subjected to the stresses of abnormal filling pressures. However, we cannot exclude the possibility that hypertrophy of the left atria may provide sufficient stress via tethering of confluent musculature to trigger the hypertrophy process in the right atria. As noted in the methods section, bridging muscular bands were encountered and divided when separating the atria. These fibers could produce an abnormal tethering stress from the left to the right atrium. A second possibility is that the right atria responded to a circulating growth factor released by the left atrium which was specific for atrial musculature. In support of the possibility of this mechanism, Field recently reported successful encoding of an atrial natriuretic factor oncogene nucleotide sequence into the genome of mice, which developed marked right atrial hypertrophy (17). Thus, a specific growth factor for atrial tissue may exist. If this latter mechanism is operative for the development of right atrial hypertrophy in these dogs in the absence of hemodynamic stress produced by malfunctioning valves, then the hypertrophy must be considered to be a failure of the control mechanisms to regulate the atrial mass to function.

It is of considerable interest to compare the effects of the development of left atrial hypertrophy on right atrial hypertrophy in these dogs with the degree to which right ventricular hypertrophy develops in conjunction with left ventricular hypertrophy. In a previous study we used a modified coarctation-banding model in puppies to produce severe left ventricular hypertrophy at one year of age (18). In these dogs the mean left ventricular body weight ratio was $100 \%$ greater than in the controls. However, the right ventricle in these dogs increased in mass by a mean of only $24 \%$. The mean left ventricular pressure was $263 \mathrm{mmHg}$ indicating a very severe hemodynamic stress was present on the left ventricle. The factors responsible for the development of right ventricular hypertrophy probably are due either to a direct hemodynamic effect or to a possible circulating growth factor. Whichever mechanism is operative, it is clear that the development of left atrial hypertrophy exerts a greater effect on the right atrium than does the development of left ventricular hypertrophy upon the right ventricle.

Before these studies, there were minimal data which defined the relationship of the atrial size in normal dogs to body weight (6). The plots in Fig. 2 for the left atria and in Fig. 3 for the right atria indicate a close relationship. Thus, the normal left atrial body weight ratio of $0.35 \pm 0.01$ and right atrial body weight ratio of $0.35 \pm 0.01 \mathrm{~g} / \mathrm{kg}$ provide normal standards for canine atrial size. It should be noted that if these data are to be used for comparison with other dogs the dissection and preparation of the atria must be similar as described in Methods.

In designing these studies we wished to compare the blood flow response in the normal and hypertrophied atria to a significant hemodynamic stress. Acute atrial fibrillation was chosen since it has been shown that this pertubation results in a marked increase in blood flow and oxygen consumption $(6,8)$. The finding of a similar response in the hypertrophied atria is of interest since it indicates that the hypertrophy process does not influence the autoregulatory ability of the atria, at least to this degree of hemodynamic stress. Although previous investigators have demonstrated that the right atria receives less blood flow per gram than the left atria during a number of hemodynamic conditions $(6,7)$ there are no data which define variations in flow within a given atrium. Thus, the present study represents the first systematic evaluation of blood flow in a number of small segments within each atria. Under the two hemodynamic conditions studied (i.e., atrial pacing at 120 bpm and acute atrial fibrillation) the segmental flow varied within the regions considerably. However, no significant systematic differences were found in either group of animals. Whether or not a different stress such as an increase in filling pressure resulting in an alteration in atrial geometry would result in segmental flow difference remains conjectural.

Regional differences were noted in blood flow in the normal dogs between the combined roof and side regions (nonappendage) and the appendage region. During control conditions both right and left atrial appendage regions had a lower flow. If we assume that blood flow is a reasonable index of atrial mechanical work (8) these data suggest that the appendage regions during control conditions were generating less need for oxygen consumption than the nonappendage regions. During atrial fibrillation a similar significant reduction in appendage flow when compared to nonappendage flow was present in the right but not the left atria. It is of interest that the flow to the left atrial appendage was markedly increased during acute atrial fibrillation perhaps indicating that the appendage may play a significant hemodynamic role.

In the hypertrophy dogs, regional flow variation in the right atria during atrial pacing at $120 \mathrm{bpm}$ and atrial fibrillation were similar to that of the normal dogs. However, the left atrial appendage flow was similar to the nonappendage flow perhaps indicating that the appendage region of the hypertrophied atria performed a similar degree of work as the nonappendage region. As discussed above there were no significant differences in atrial pressure between normal and hypertrophied atria dogs. However, this finding may indicate a different distribution of mechanical work in the hypertrophied atria during control conditions. The regional response of the hypertrophied atria to atrial fibrillation was similar to the normal.

Adenosine was infused to produce a maximum reduction in vascular resistance which has been equated to the estimation of coronary flow reserve (i.e., the lower the vascular resistance the greater the reserve). A number of investigators have demonstrated that in the hypertrophied left (2-4) and right ventricle (1) the coronary flow reserve is reduced when compared to normal. This has been interpreted as indicating that the vasculature during the hypertrophy process does not enlarge proportionally to the same extent as the myocardial cells. It has been postulated that this relationship to coronary flow reserve may explain the abnormal perfusion which has been found in the working hypertrophied ventricle, but there are no previous data defining the coronary flow reserve in the hypertrophied atria. Our present studies clearly indicate that in both the right and left atria the hypertrophy process is accompanied by a reduction in coronary flow reserve. In addition, a similar finding was noted in the appendage and nonappendage regions when examined separately for both the right and left atria. Thus, it is apparent that the hypertrophy process for both the right and left atria is associated with a reduction in coronary flow reserve such as is seen in the hypertrophied ventricles. 
This finding was not related to other factors between hypertrophy and normal dogs since left ventricular coronary flow reserve was similar for both the normal and hypertrophied dogs. Thus, it is apparent that the reduction in coronary flow reserve found in the hypertrophied ventricles is seen also when the hypertrophy process occurs in the atria. Although the coronary flow reserve is reduced in atrial hypertrophy, the actual physiologic importance of this phenomenon is unknown. Obviously the flows recorded during adenosine infusion are greater than those during physiologic stresses of atrial fibrillation and are likely to be greater than those during increases in flow secondary to other physiologic stresses. Thus, the fact that coronary flow reserve is reduced during atrial hypertrophy does not indicate that the atria become ischemic under physiologic stresses.

\section{Acknowledgments}

Dr. Bauman wishes to especially thank Richard S. Stack for initiating his interest in research. The authors wish to express their appreciation to the following: C. Frank Starmer and Marge Dietz for data processing and statistical analyses; H. Newton Pleasant, Cornelius A. Davis III, and Nancy Marshburn for technical assistance; Marie Anderson for bibliographic research; and Cheryl L. Everette for secretarial support.

Supported, in part, by the National Institutes of Health grant HL-18468, the Medical Research Service of the Veterans Administration, and by 127B9. Dr. Bauman is an Associate Investigator with the Veterans Administration.

\section{References}

1. Archie, J. P., D. E. Fixler, D. J. Ullyot, G. D. Buckberg, and J. I. E. Hoffman. 1974. Regional myocardial blood flow in lambs with concentric right ventricular hypertrophy. Circ. Res. 34:143-154.

2. Mueller, T. M., M. L. Marcus, R. E. Kerber, J. A. Young, R. W. Barnes, and F. M. Abboud. 1978. Effect of renal hypertension and left ventricular hypertrophy on the coronary circulation in dogs. Circ. Res. 42:543-549.

3. Rembert, J. C., L. H. Kleinman, J. M. Fedor, A. S. Wechsler, and J. C. Greenfield, Jr. 1978. Myocardial blood flow distribution in concentric left ventricular hypertrophy. J. Clin. Invest. 62:379-386.

4. Bache, R. J., T. R. Vrobel, C. E. Arentzen, and W. S. Ring. 1981. Effect of maximal coronary vasodilation on transmural myocardial perfusion during tachycardia in dogs with left ventricular hypertrophy. Circ. Res. 49:742-750.
5. White, F. C., M. Sanders, T. Peterson, and C. M. Bloor. 1979. Ischemic myocardial injury after exercise stress in the pressure-overloaded heart. Am. J. Pathol. 97:473-488.

6. McHale, P. A., J. C. Rembert, and J. C. Greenfield, Jr. 1983. Effect of atrial fibrillation on atrial blood flow in conscious dogs. Am. J. Cardiol. 51:1722-1727.

7. Neill, W. A., D. Sewell, M. Gopal, J. Oxendine, and L. Painter. 1980. Independent regulation of atrial coronary blood flow by atrial contraction rate in conscious dogs. Pfluegers Arch. Eur. J. Physiol. 388:193-195.

8. White, C. W., R. E. Kerber, H. R. Weiss, and M. L. Marcus. 1982. The effects of atrial fibrillation on atrial pressure-volume and flow relationships. Circ. Res. 51:205-215.

9. Phillips, H. R., R. S. Stack, J. C. Rembert, and J. C. Greenfield, Jr. 1982. A technique to inject microspheres into the left atrium of awake dogs without thoracotomy. Am. J. Physiol. 243 (Heart Circ. Physiol. 12):H488-H490.

10. Rembert, J. C., L. M. Boyd, W. P. Watkinson, and J. C. Greenfield, Jr. 1980. Effect of adenosine on transmural myocardial blood flow distribution in the awake dog. Am. J. Physiol. 239 (Heart Circ. Physiol. 8):H7-H13.

11. Keith, A., and M. Flack. 1907. The form and nature of the muscular connection between the primary divisions of the vertebrate heart. J. Anat. Physiol. 41:172-189.

12. Bauman, R. P., J. C. Rembert, S. I. Himmelstein, P. E. Klotman, and J. C. Greenfield Jr. 1987. Effect of atrial natriuretic factor on transmural myocardial blood flow distribution in the dog. Circulation. 76:705-709.

13. Swain, J. L., J. P. Parker, P. A. McHale, and J. C. Greenfield, Jr. 1979. Effects of nitroglycerin and propanolol on the distribution of transmural myocardial blood flow during ischemia in the absence of hemodynamic changes in the unanesthetized dog. J. Clin. Invest. 63:947-953.

14. Wallenstein, S., C. L. Zucker, and J. L. Fleiss. 1980. Some statistical methods useful in circulation research. Circ. Res. 47:1-9.

15. Gardin J. M., W. L. Henry, D. D. Savage, J. H. Ware, C. Burn, and J. S. Borer. 1979. Echocardiographic measurements in normal subjects: evaluation of an adult population without clinically apparent heart disease. J. Clin. Ultrasound. 7:439-447.

16. Legato, M. J. 1979. Cellular mechanisms of normal growth in the mammalian heart. Circ. Res. 44:250-262.

17. Field, L. J. 1988. Atrial natriuretic factor-SV40 T antigen transgenes produce tumors and cardiac arrhythmias in mice. Science (Wash. DC). 239:1029-1033.

18. Kleinman, L. H., A. S. Wechsler, J. C. Rembert, J. M. Fedor, and J. C. Greenfield, Jr. 1978. A reproducible model of moderate to severe concentric left ventricular hypertrophy. Am. J. Physiol. 3 (Heart Circ. Physiol. 5):H515-H524. 